\title{
Estimating North Pacific right whale Eubalaena japonica density using passive acoustic cue counting
}

\author{
Tiago A. Marques ${ }^{1,2, *}$, Lisa Munger ${ }^{3}$, Len Thomas ${ }^{1}$, Sean Wiggins ${ }^{3}$, \\ John A. Hildebrand ${ }^{3}$ \\ ${ }^{1}$ Centre for Research into Ecological and Environmental Modelling, The Observatory, Buchanan Gardens, \\ University of St Andrews, St Andrews KY16 9LZ, UK \\ ${ }^{2}$ Centro de Estatística e Aplicações da Universidade de Lisboa, Bloco C6, Piso 4, Campo Grande, 1749-016 Lisboa, Portugal \\ ${ }^{3}$ Scripps Institution of Oceanography, University of California San Diego, 9500 Gilman Drive, La Jolla, \\ California 92093-0205, USA
}

\begin{abstract}
We present a method for estimating animal density from fixed passive acoustic detectors, and illustrate it by estimating the density of North Pacific right whales Eubalaena japonica in the areas surrounding 3 hydrophones deployed in the southeastern Bering Sea in 2001 to 2002 and 2005 to 2006. Input data were the distances to detected right whale calls, estimated using a normal mode sound propagation model, and call production rate, estimated from encounters by survey vessels with right whale groups. Given the scarcity of information about this highly endangered species, we also extrapolate our results to provide a tentative estimate of the total population size in shelf waters of the eastern Bering Sea. This gives a point estimate of 25 animals (CV 29.1\%; $95 \%$ confidence interval 13-47), which agrees well with what little is known for this species. We discuss the assumptions underlying the method. Obtaining more reliable values requires a larger sample of randomly located hydrophones, together with improved estimates of call rate.
\end{abstract}

KEY WORDS: Bering Sea $\cdot$ Point transects $\cdot$ Distance sampling $\cdot$ Normal mode propagation $\cdot$ Abundance estimation $\cdot$ Acoustic recording package $\cdot$ ARP $\cdot$ High frequency acoustic package $\cdot$ HARP

\section{INTRODUCTION}

A key question asked when investigating an animal population is 'How many are there?' Abundance, or equivalently density, is a fundamental quantity required to understand and address other more complex issues in population ecology and conservation.

In the last few years, passive acoustic surveying has been put forward as a viable option for estimating cetacean density (Mellinger et al. 2007b). For example, sperm whale abundance has been estimated using distance sampling line transects where distances were obtained using acoustics (Leaper et al. 2000, Hastie et al. 2003, Barlow \& Taylor 2005, Lewis et al. 2007), giving more detections from larger ranges than would have been obtained using only the conventional visual methods. In addition to potentially surveying a larger area, acoustic methods present additional advantages over visual surveys, being (1) less dependent on weather conditions, (2) not restricted to daylight, (3) able to cope with animals that spend a large proportion of time under water (while vocalizing). However, acoustic methods will not be viable in all cases: they require knowledge of the vocal behavior of the target species, and will work best for species that produce easily detectable, frequent vocalizations, but as we show here, they can also work with relatively infrequent callers. Here, we focus on fixed acoustic sensors. Acoustic methods are well suited to fixed deployments, since recording devices can be moored for long periods of time and then recovered later for subsequent processing. This enables good temporal sampling, unlike 
visual or acoustic line transect methods that are typically considered a snapshot in time. However, significant effort is required with fixed sensors to achieve good spatial coverage, something we return to in the 'Discussion'.

The North Pacific right whale Eubalaena japonica is considered one of the most endangered whale species in the world, and one for which obtaining further basic biological and ecological information is crucial for effective management and conservation (LeDuc et al. 2001). Two stocks of right whales are thought to exist in the North Pacific: an eastern and a western population. The eastern stock is thought to be smaller in number, and its current size might be too small to ensure its persistence (Brownell et al. 2001). This is further supported by recent published work based on markrecapture methods (Wade et al. 2011, N = 31 animals, $95 \%$ CI 23-54, based on photo ID data, and $\mathrm{N}=28$, $95 \%$ CI 24-42, based on genetic data). Better estimates of population size are fundamental to assess a population's chances of recovery. However, this species is particularly difficult to survey using visual methods, because density is now so low that even its current distribution area is uncertain. Furthermore, the number of animals detected in a given survey would not be enough to fit a conventional distance sampling detection function, or to provide effective cost-effort trade offs for mark-recapture methods based on photo identification or DNA from biopsies.

Passive acoustic monitoring has been used to detect seasonal trends in occurrence for both the North Pacific right whale (Munger et al. 2008) and the North Atlantic right whale Eubalaena glacialis (Mellinger et al. 2007a). Trends are assessed interpreting the raw counts of detected sounds as an index of abundance. Although these studies suggest that calling rates (Munger et al. 2008) or proportion of time with calls present (Mellinger et al. 2007a) may be positively associated with abundance, they also note that trends in detected call rates may vary depending on behavioral context and other factors. In order to turn the number of sounds detected into density, one needs to account for both the detectability of sounds and the production rate of such sounds.

In a recent paper, Marques et al. (2009) presented a cue-counting approach that allows the estimation of cetacean density based on the number of cues detected at a set of hydrophones, where a cue is an animal vocalization. To convert the number of detected cues to density of cues, one needs to characterize the detection process, namely the proportion of false positives and of missed cues (within a certain radius around the acoustic sensors). The proportion of missed cues, or equivalently the probability of detecting a cue, is a challenging quantity to obtain. Marques et al.
(2009) required acoustic dive Dtag (Johnson \& Tyack 2003) data from geo-referenced animals in order to estimate the detection probability, as a function of distance and animal-hydrophone angle, through a binary regression approach. Further, conversion of cue density into animal density required estimation of the average cue production rate from the DTag data. In the methods proposed here, we also require a cue production rate. However, obtaining the detection probability is far simpler, because, one can obtain the distances to detected cues using a method that does not require tag data (see 'Materials and methods: Obtaining distances'). Given these distances, estimation is carried out using a conventional cue-counting distance sampling approach (Buckland et al. 2001).

Here, we present an example of how data from a set of 3 fixed passive acoustic sensors can be used to estimate density of the North Pacific right whale in the vicinity of the sensors. Given the scarcity of data on this species, we also extrapolate this number to the continental shelf of the eastern Bering Sea, an area presumed to be occupied by this species from May to October. The present paper has 2 distinct objectives: to present a cue-counting method that can be used under different conditions to estimate density and abundance of cetaceans, and to provide an estimate for one of the most endangered large whale populations in the world.

\section{MATERIALS AND METHODS}

Acoustic deployments. Recordings were made using 3 autonomous acoustic sensors. The first recording was from August 2001 to July 2002 and used an autonomous seafloor-mounted acoustic recording package (ARP; Wiggins 2003) with an effective bandwidth from 10 to $250 \mathrm{~Hz}$. The other 2 recordings were from 2005 to 2006 and used high-frequency ARPs (HARPs; Wiggins \& Hildebrand 2007) with a bandwidth of $10 \mathrm{~Hz}$ to $20 \mathrm{kHz}$. These were configured in-line with the National Oceanic and Atmospheric Administration (NOAA) Pacific Marine Environmental Laboratory (PMEL) oceanographic moorings to minimize potential instrument loss as sometimes experienced with seafloor-mounted packages as a result of severe weather and trawl fishing operations. The electronic noise floor at $100 \mathrm{~Hz}$ for the ARP was $29 \mathrm{~dB}$ re 1 $\mu \mathrm{Pa}^{2} \mathrm{~Hz}^{-1}$, and for the HARP was $42 \mathrm{~dB}$ re $1 \mu \mathrm{Pa}^{2} \mathrm{~Hz}^{-1}$, both of which are well below ambient noise levels in the Bering Sea. A summary of the characteristics of each deployment is presented in Table 1 and the locations of the sensors are shown in Fig. 1.

Right whale up-calls (e.g. McDonald \& Moore 2002) were detected in long-term recordings using a combined approach of automated detection (spectrogram 
Table 1. Summary of acoustic sensor data. Deployment location (latitude, longitude, depth), start and end of the recording; number of recording hours in the May to October period considered for inference; corresponding number of calls detected during that period (numbers of calls before truncation are shown inside parentheses); and encounter rate (ER) in calls $\mathrm{h}^{-1}$. Dates are given in $\mathrm{dd} / \mathrm{mm} / \mathrm{yy}$

\begin{tabular}{|lcccccccc}
\hline Sensor & Latitude $\left({ }^{\circ} \mathrm{N}\right)$ & Longitude $\left({ }^{\circ} \mathrm{W}\right)$ & Depth $(\mathrm{m})$ & Start & End & Duration (h) & No. of calls & ER \\
\hline M2 & 56.860 & 164.058 & 71 & $23 / 04 / 05$ & $16 / 01 / 06$ & 4393 & $1272(1338)$ & 0.29 \\
M4 & 57.860 & 168.877 & 71 & $25 / 09 / 05$ & $25 / 01 / 06$ & 865 & $70(71)$ & 0.08 \\
C & 56.672 & 163.008 & 70 & $31 / 08 / 01$ & $28 / 07 / 02$ & 3577 & $987(1120)$ & 0.28 \\
\hline
\end{tabular}

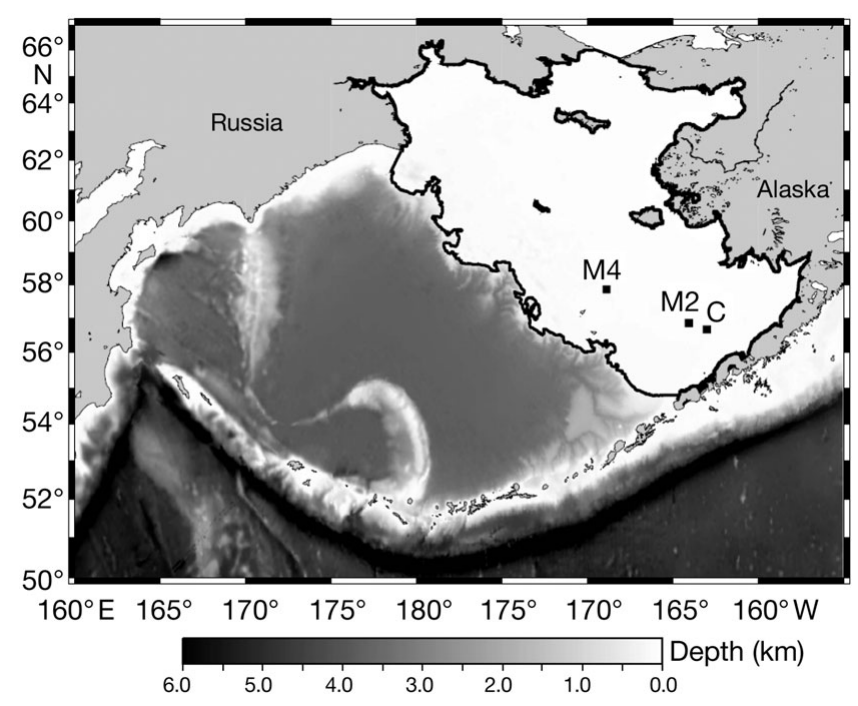

Fig. 1. Bering Sea, with location of sensors (C, M2, and M4) shown. Land masses are light gray. The eastern Bering Sea shelf is outlined with a thick black line including the $200 \mathrm{~m}$ depth contour along its western edge. Bathymetry data were taken from Amante \& Eakins (2009)

cross-correlation), manual verification, and additional searching (Munger et al. 2005, 2008). Cue rates used in this paper were obtained using right whale calls that were confirmed aurally and visually by an experienced analyst.

Ambient noise was measured within the frequency band of right whale calls by bandpass filtering data with corner frequencies within $10 \mathrm{~Hz}$ of the minimum and maximum frequency of each call (Munger et al. in press). Root-mean-square amplitude counts were obtained for 1 to $3 \mathrm{~s}$ of noise immediately before or after the right whale call and converted to absolute received levels based on laboratory calibration of hydrophones (McDonald 2006). This noise measurement was obtained initially to determine signal-tonoise ratio (SNR) of right whale calls and therefore was measured within the same band and near the same time as each call (Munger et al. in press). The background noise data are used here as a potential covariate in the detection function (see 'Detection probability' below).
Estimation approach. The methods proposed here are essentially conventional cue-counting distance sampling methods (see Buckland et al. 2001 for details, and the 'Discussion' for a list of assumptions). While cue counting was originally developed in the context of line transect surveys, it is well suited to work from fixed points (e.g. Buckland 2006). The novelty here is that the distances to detected cues are obtained from single acoustic sensors. Here, we use right whale up-calls as cues.

The estimator used here follows directly from what was presented by Marques et al. (2009), with minor differences accounting for unequal time sampling of sensors and the a priori need for left truncation of distances in the analysis. Given $n$ detected cues in a time period $T_{K}$ (sum of time periods in each of $K$ sensors), density $D$ can be estimated by the formula

$$
D=\frac{n(1-c)}{a p T_{K} r}
$$

where $C$ is the proportion of false positive detections (sounds detected and classified as cues of interest which in fact were not), $p$ is the probability of detecting a cue given that it is produced within the area surveyed, $a$, and $r$ is the cue production rate. In conventional distance sampling applications, $a$ is equal to $\pi w^{2}$ where $w$ is a right truncation distance (distances larger than $w$ are not considered in the analysis). Here, we $a$ priori expect it to equal $\pi w^{2}-\pi w_{1}^{2}$, where $w_{1}$ represents a left truncation distance, because distance cannot be reliably measured to close-by detections (see 'Obtaining distances' below). Note that in this application, and given the amount of human effort involved in call detection, we safely assumed no false positives, which simplifies the estimator above as $C=0$.

Scope of inference. Despite having recordings from outside the period May to October, we purposely restricted our analysis to this period, when the whales were assumed to be over the continental shelf of the Bering Sea (consistent with data presented by Brownell et al. 2001 and Clapham et al. 2004). Given the assumption that animals distribute themselves randomly over the shelf in both time and space, the obtained density estimate can be multiplied by the area of the shelf to obtain an abundance estimate for the entire eastern Bering Sea continental shelf (Fig. 1). 
Obtaining distances. A key quantity in Eq. (1) that needs to be estimated is $p$, the probability of detecting a cue as a function of its distance. This is done in a traditional distance sampling framework, for which distances to detected cues need to be measured.

Distances to detected cues could be obtained by time-difference-of-arrival (TDOA) of cues on 3 or more acoustic sensors (e.g. McDonald et al. 1995). However, this approach requires that a larger number of closelyspaced acoustic sensors are available, configured into a time-synchronized array, as well as an extra data processing stage (matching of calls across different sensors). Instead, we employed a method that allows data from single sensors to determine the distance to calling animals.

Distances to right whale up-calls were obtained from single sensors by modeling the dispersion of normal modes in a shallow waveguide. An initial range (distance) was calculated using the arrival times of modes across a given frequency within a single right whale call spectrogram, and a synthetic upsweep containing the first 6 modes was modeled using this range and overlaid on the actual call spectrogram. The range and other model parameters were adjusted manually until the best fit was obtained, as determined qualitatively by the analyst. See Munger et al. (in press) and Wiggins et al. (2004) for details on normal mode propagation and application to right whale calls in the southeastern Bering Sea. The main advantage of this method over the approach presented by Marques et al. (2009) is that the distances, and hence detection probability, can be obtained using information collected by the acoustic sensors themselves, bypassing the need for ancillary information (like tag data).

Given call source levels, transmission loss, and average background noise levels in the Bering Sea, detection distances of up to $100 \mathrm{~km}$ were expected (Wade et al. 2006, Munger et al. in press). Ranges of less than $20 \mathrm{~km}$ were difficult to estimate using the model, due to very little dispersion in mode arrivals resulting in ambiguity in the choice of mode number, the parameter to which the model is most sensitive (Wiggins et al. 2004). To avoid potentially severe measurement error at small distances, a left truncation distance of $w_{1}=$ $20 \mathrm{~km}$ was used.

Detection probability. Given the distances to detected calls, estimating $p$, or equivalently the effective detection radius of a sensor, is obtained using standard distance sampling methods (Buckland et al. 2001).

The methods are based on the notion of a detection function, $g(r)$, which represents the probability of detecting a cue given that the animal which produced it is at distance $r$ from the sensor. It can be shown that $p$ is the mean value of the detection function with respect to the available distances, i.e. that

$$
p=\int_{w_{1}}^{W} g(r) \pi(r) \mathrm{d} r
$$

where $\pi(r)$ represents the probability density function of available distances, which is assumed known (Buckland et al. 2001). Note the lower limit of integration is different from the usual formulae to account for left truncation.

A set of plausible candidate parametric models for $g(r)$ is assumed, and series expansion terms might be added for additional flexibility (Buckland et al. 2001). The software Distance (Thomas et al. 2010) was used to fit these models to data. We used the hazard rate and half-normal detection functions as candidate models, with cosine series expansion terms as required for better fit. Additional covariates can be included in the model if they are believed to influence the detection process (e.g. Marques et al. 2007). Here we tested the above described measure of ambient noise, which a priori could influence call detectability. Choice between competing models was based on the minimum Akaike Information Criterion (AIC), which provides a relative measure of fit. For the models with and without covariates, we manually set the number of series expansion terms to 0 and 2, respectively, to avoid implausible fits (e.g. non-decreasing detection functions). We also checked absolute fit of the models using chi-squared, Kolmogorov-Smirnov, and Cramer-von Mises tests. All of these are available in the software Distance.

Cue production rate. Individual calling rates for North Pacific right whales were estimated from recordings made during vessel-based cetacean surveys in the southeastern Bering Sea. Surveys were conducted in July to August 2002 aboard the NOAA ship 'McArthur' (LeDuc 2004), in August 2004 aboard the 'Alaskan Enterprise' (Wade et al. 2006), and in September 2004 aboard the NOAA ship 'McArthur II' (Wade et al. 2006). Right whale calls were recorded using directional sonobuoys (type AN/SSQ-53D), and species identification was confirmed and group size estimated by visual observers. Data were included only from recordings when right whale calls were detected with certainty and right whales were concurrently or subsequently detected visually. We estimated the call rate by the weighted mean of the call rates (weighted by recording time) in each of 8 encounters with North Pacific right whales. The corresponding weighted average variance was calculated using the formula suggested by Gatz \& Smith (1995).

Variance estimation. Assuming the independence of the random components of the density estimator (Eq. 1), the variance of the density estimate can be approximated by the delta method (Seber 1982) as

$$
\operatorname{vâr}(\hat{D})=\hat{D}^{2}\left[\mathrm{CV}^{2}(n)+\mathrm{CV}^{2}(\hat{p})+\mathrm{CV}^{2}(\hat{r})+\mathrm{CV}^{2}(\hat{c})\right]
$$


timate, i.e. the standard error of the estimate divided by the estimate and the hats denote an estimated quantity. This estimation is implemented in Distance, given that the appropriate variances are provided. Given the formula above, one can evaluate the percentage of the variance due to each random component.

The variance in $n$ was obtained as the empirical variance of the number of detected calls per unit time per sensor. Due to the small number of sensors and the corresponding difficulty in estimating an empirical variance, we also considered estimating the variance assuming an overdispersed Poisson distribution with an overdispersion factor of 2 (as suggested by Buckland et al. 2001). Variance in cue rate was obtained as explained in the previous subsection. The variance in detection probability is an output of Distance, calculated using the inverse of the information matrix resulting from the maximum likelihood estimation of the detection function parameters. In our application the false positive proportion $c$ is assumed to be 0 , so the $\mathrm{CV}$ of $c$ is also 0 .

\section{RESULTS}

\section{Number of detections}

In total, 8835 recording hours were available during the period May to October, over which we detected a total of 2529 right whale calls. Discrimination by sensor leads to 4393 recording hours for sensor M2, 865 for M4, and 3577 for $C$, with respectively 1338, 71, and 1120 calls detected before truncation (Table 1). After left and right truncation (see details in the following subsection), this corresponds to $0.29,0.08$, and 0.28 detected calls $\mathrm{h}^{-1}$, leading to an average (weighted by sensor recording time) encounter rate of 0.26 detected calls $\mathrm{h}^{-1}$, with a CV of $10.5 \%$. The alternative variance estimator, assuming an overdispersed Poisson distribution for calls, gave a CV of $2.93 \%$. The former is therefore a more conservative value and we use it throughout for the variance estimates.

\section{Detection probability}

We selected 20 and $80 \mathrm{~km}$ as left and right truncation distances, resulting in the loss of 84 and 116 observations, respectively. Conditional on this truncation choice, the hazard rate model was preferred over the half-normal $(\triangle \mathrm{AIC}=34.93$ to the half normal model). As expected, ambient noise proved to be important in explaining detectability ( $\triangle \mathrm{AIC} 16.36$ to the corresponding hazard rate model without covariate), with increasing noise resulting in a decrease in detection probability. The resulting model fits were also more plausible with the hazard rate model than the half-normal model, because a priori a wide shoulder of perfect detectability was expected. Goodness-of-fit tests showed no departure from the assumed model, and visual inspection of the fitted function (Fig. 2) and quantile-quantile-plots (not shown) revealed no systematic problems. Therefore, we proceed with inferences based on the hazard rate model with the noise covariate. We note that while abundance estimates are virtually the same with the model without the noise covariate, its inclusion considerably reduces the $\mathrm{CV}$ on the estimated detection probability. The fitted detection function suggests $g(30)=1$, which is reassuring, given the use of the left truncation. The fit is compatible with simple considerations about sound source
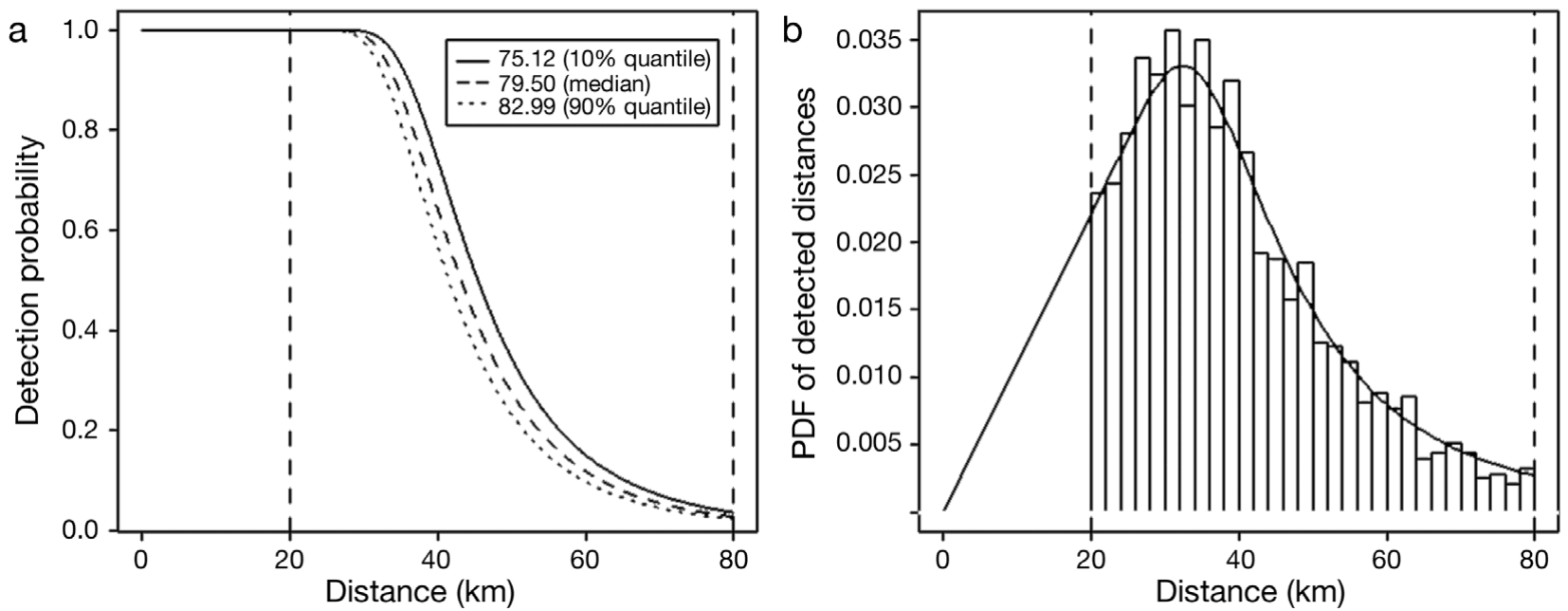

Fig. 2. Distances to detected right whale calls and fitted model: (a) shows the detection function (as a function of distance, for 3 values of the noise covariate, namely the 10,50, and $90 \%$ quantile of the observed distribution) and (b) corresponds to the probability density function (PDF) of detection distances, and goodness-of-fit could be judged based on this plot. Vertical dashed lines represent the left and right truncation distances 
levels and sound propagation properties in this area; $p$ was estimated to be 0.29 with a $\mathrm{CV}$ of $1.76 \%$.

\section{Cue production rate}

Eight recordings taken over a total of $127 \mathrm{~h}$ were used to estimate call production rate (Table 2). The average cue rate was estimated to be 1.743 calls per whale per hour with a CV of $27.0 \%$.

\section{Density and abundance}

The estimated whale density was 0.26 (CV: 29.0; $95 \%$ CI: 0.136-0.499) whales per $10000 \mathrm{~km}^{2}$. Assuming that this density is representative of the continental shelf area of the Bering Sea, an area of $950000 \mathrm{~km}^{2}$ gives an estimate of right whale abundance in this area of 25 whales (95\% CI: 13-47). The variance associated with the density or abundance estimates can be partitioned according to the random components involved. The largest contributor was the cue rate $(86.5 \%)$, followed by the encounter rate $(13.1 \%)$, and a distant third was the detection function $(0.4 \%)$. Using the alternative overdispersed Poisson variance estimator for encounter rate gave a very similar estimate of variance in density (CV: $27.2 \%$ ).

\section{DISCUSSION}

One objective of this paper was to provide a proof-ofconcept example of how one can estimate cetacean density from acoustic sensors without the need for data other than those collected from the acoustic sensors themselves and cue rates obtained from ancillary field

Table 2. Eubalaena japonica. Data from 8 right whale recordings used to estimate the call production rate. Columns represent the vessel, the recording start date $(\mathrm{dd} / \mathrm{mm} / \mathrm{yy})$ and time, the number of calls, the recording duration, the number of whales in the group recorded, and the call rate (in calls per whale per hour). Dates are given as dd/mm/yy

\begin{tabular}{|lccccc|}
\hline Vessel & Start & $\begin{array}{c}\text { No. of } \\
\text { calls }\end{array}$ & $\begin{array}{c}\text { Duration } \\
\text { (h) }\end{array}$ & $\begin{array}{c}\text { No. of } \\
\text { whales }\end{array}$ & Rate \\
\hline 'McArthur' & $25 / 08 / 02,00: 00 \mathrm{~h}$ & 3 & 3.77 & 2 & 0.40 \\
'McArthur' & $26 / 08 / 02,00: 00 \mathrm{~h}$ & 74 & 36.96 & 3 & 0.67 \\
'McArthur' & $27 / 08 / 02,09: 48 \mathrm{~h}$ & 14 & 5.80 & 1 & 2.41 \\
'McArthur' & $27 / 08 / 02,21: 30 \mathrm{~h}$ & 4 & 8.35 & 1 & 0.48 \\
'McArthur' & $28 / 08 / 02,09: 29 \mathrm{~h}$ & 11 & 5.98 & 2 & 0.92 \\
'McArthur' & $28 / 08 / 02,21: 00 \mathrm{~h}$ & 75 & 10.50 & 2 & 3.57 \\
'Alaskan Enterprise' & $10 / 08 / 04,12: 10 \mathrm{~h}$ & 82 & 5.68 & 2 & 7.22 \\
'McArthur II' & $07 / 09 / 04,16: 51 \mathrm{~h}$ & 2142 & 49.92 & 23 & 1.87 \\
(SPLASH) & & & & & \\
\hline
\end{tabular}

observations. This approach worked well here because the combination of the species, environment, and acoustic settings permitted obtaining a model that estimates distance from data collected from single sensors, and hence using a conventional distance sampling cue counting approach. However, normal mode propagation modeling is only suitable for particular areas (i.e. uniformly flat and shallow) and may not be widely applicable in other habitats. Notwithstanding, there are several other approaches that have been used to obtain distances to detected cetacean vocalizations from single sensors or arrays of closely-spaced, time-synchronized sensors. These include use of multipath detections (e.g. Cato 1998, McDonald \& Fox 1999, Aubauer et al. 2000, Sirovic et al. 2007), received sound levels (e.g. Cato 1998, McDonald \& Fox 1999), and TDOA on closely spaced sensors (e.g. McDonald et al. 1995). Hence the analytic methods presented here may be applicable in a wide range of circumstances.

There are possible alternatives to estimate density from data collected in acoustic sensors and cue rates, with the key difference being how one estimates the detection function. For example, a detection function might be obtained using an acoustic propagation model combined with sound source characteristics (e.g. Zimmer et al. 2008). On the other hand, one could implement spatially explicit capture-recapturebased methods, where associations of sounds across hydrophones are used to estimate density while bypassing the need for localization (e.g. Marques et al. 2010).

\section{Distance sampling assumptions}

Several assumptions are required for the conventional distance sampling methods to work. We present them here in the context of cue counting. We assume that: (1) the distribution of distances to cues (whether detected or not), $\pi(r)$, is known; (2) all calls produced on or near the point are detected, i.e. $g(0)=1$; (3) false positive detections are correctly accounted for; (4) distance measurements to calls are error free; and (5) detected distances are statistically independent. Below we present a critical assessment of how likely these assumptions are to hold, and possible consequences of failure. Note that the usual assumption about animal movement in conventional distance sampling methods is not necessary here, because whale calls, not animals, are the object being detected, 
and the calls are for practical purposes instantaneous and therefore static

(1) Known distribution of available distances. For conventional distance sampling methods to work, one must know the horizontal distribution of distances of cues (detected or not) with respect to the acoustic devices, $\pi(r)$. This should usually be enforced by design, by using a sufficient number of sensors randomly allocated in the area of interest, so that animal (and hence cue) distribution is random with respect to sensor location (Buckland et al. 2001). Here, we only used 3 sensors with non-random placement, and therefore the quality of our estimate of detection probability is dependent on how closely, such an assumption was met in this case. The fact that the estimate obtained is so close to other estimates (Wade et al. 2011 estimated an abundance of 28 or 31 whales, depending on the data used) for the population is reassuring. Nonetheless, in future implementations of these methods, special care should be given to sampling design, in particular to the number and location of sensors. In general, 20 or more sensors, located on a systematic random grid, would be preferred.

(2) $\boldsymbol{g}(\boldsymbol{0})=\mathbf{1}$. Given that source levels of right whale up-calls in the Bering Sea were estimated at over $175 \mathrm{~dB}$ re $1 \mu \mathrm{Pa}$ at $1 \mathrm{~m}$ and average ambient noise within the right whale up-call band was 72 to $91 \mathrm{~dB}$ re $1 \mathrm{\mu Pa}^{2} \mathrm{~Hz}^{-1}$ (Munger et al. in press), right whale calls at close ranges would have sufficient SNR to be easily detected. In addition, the fitted detection function (Fig. 2) suggests that detection probability has a wide shoulder out to around $30 \mathrm{~km}$, although given the $20 \mathrm{~km}$ left truncation used, this is based solely on distances obtained between 20 and $30 \mathrm{~km}$.

(3) False positives correctly accounted for. In the current study, given the amount of manual processing required to obtain the distances and the distinctive nature of right whale calls compared to other noises in the region, we were justified in assuming that no false positive detections entered the distance sampling analysis.

(4) No distance measurement error. Distances were obtained here using a predictive acoustic model, and therefore there is a random error associated with their calculation. Preliminary assessment using a subset of distances where TDOA measurements could be used as a ground truth (L. Munger unpubl. data) suggests that the estimated distances are unbiased, with a CV of around $17 \%$. This level of error would produce a positive bias in density estimates of approximately $10 \%$, assuming the calculated distances follow a gamma distribution (Marques 2007). However, TDOA-based distances are themselves subject to error, so the true CV in the distance we used is likely less than $17 \%$. On the other hand, different human operators could analyze a random sample of distances and characterize the variance associated with any operator-subjective decisions. Hence, a natural extension to the methods presented here would be to incorporate measurement error in the estimation process, following the methods of Borchers et al. (2010).

The distances required for analysis are horizontal distances from sensor to call, since it is density per unit area that is being calculated. In our application, given the shallow water depth and large detection ranges, direct distance and horizontal distances were almost identical. In other applications this may not be the case. If animals are known to vocalize at a narrow range of depths (e.g. close to the surface), then horizontal distances can easily be calculated, assuming a single depth. If the depth distribution is known (e.g. from tag data), but broad, then the horizontal distance will not be known with certainty, leading to a measurement error problem that can again be treated using methods such as those of Borchers et al. (2010). Some sensors allow estimation of both range and vertical angle, in which case horizontal distance can be calculated without knowledge of animal depth distribution.

The process for obtaining the distances in our example is currently labor intensive. The development of routines for automatic distance estimation under similar settings might be an interesting research area in the interface between acoustics and statistics.

(5) Detected distances are statistically independent. Given that an animal produces multiple calls, it is likely that the independence assumption is violated. This should not cause bias in the estimates; however, model selection, goodness-of-fit and variance estimation are affected. The effect on model selection is a tendency to select models with too many parameters - in our case a simpler model with no noise covariate resulted in very similar results, so this is not a concern. Goodness-of-fit statistics are more likely to show poor fit, but in our case the fit was satisfactory. Detection function variance is likely to be underestimated, but in our case the variance due to the other random components (encounter and cue rates) was so dominant (more than $99 \%$ of the total variance in density) that even a moderate increase would have little effect on the overall variance. In summary, we do not feel that non-independence of distances is a major issue, as indeed is typical when this occurs in distance sampling surveys (Buckland et al. 2001).

Other considerations. We used left truncation at 20 $\mathrm{km}$ because distances could not accurately be determined for closer calls. An alternative would have been to perform an analysis on grouped distance data, placing all detections made within $20 \mathrm{~km}$ into a single distance interval. This has the advantage of 
using more of the data, as detections within $20 \mathrm{~km}$ are included in the analysis, but the disadvantage of turning the 'exact' data from distances greater than $20 \mathrm{~km}$ into intervals. As a check, we performed this analysis, using a single interval for 0 to $20 \mathrm{~km}$ and then $5 \mathrm{~km}$ intervals up to $80 \mathrm{~km}$, and found it produced nearly identical results, with an estimate of 1 whale fewer (24, with $95 \% \mathrm{CI}$ : 12-45). One disconcerting finding, however, was that many fewer calls were detected in the 0 to $20 \mathrm{~km}$ interval than expected, given the fitted detection function (observed 84, expected 505). Although it is possible that this is indicative of a failure to detect calls at close distances (Assumption 2, above), for the reasons given above we think this is unlikely. Instead, it seems more likely that this indicates a failure of the assumption of known distribution of calls (Assumption 1, above), with fewer than expected groups of whales coming within close range of the sensors during the monitoring period. We emphasize that a large number of (systematic) randomly located sensors is a requirement for reliable inference, and should be a primary design criterion for any future passive acoustic density survey.

While we provide a tentative abundance estimate for the entire eastern Bering Sea continental shelf, on top of all the previously stated assumptions, and as stated explicitly in 'Materials and methods', this estimate is also based on an untested assumption about animal distribution over time and space. However, our estimate is supported by similar numbers obtained by Wade et al. (2011) using mark-recapture analyses.

\section{Cue rate}

We have assumed that the cue rate used is the mean cue rate that occurred during the acoustic survey. However, this survey and cue rate data were not coincident in time. Despite some published work on variation in North Atlantic right whale calling rates (e.g. Matthews et al. 2001, Van Parijs et al. 2009), there is little concrete information about cue rate and its relation to potentially important covariates. Therefore, although likely, it is not known whether, or how, cue rates are dependent on external factors (for example the time of year or group size). Also, the actual variance one would like to incorporate in the estimate would be the between-individual variance in the cue rates observed during the survey, while here we had to use the variance on cue rates across different groups of animals. Since results are dependent on the adequacy of this cue rate estimate, and also because this is the component contributing more, by far, to the overall variance in abundance estimates, efforts should be made to obtain better estimates of cue rate, as well as to assess whether it changes as a function of covariates.

Nonetheless, these results are remarkably consistent with rates found for North Atlantic right whales Eubalaena glacialis, a closely related species, measured in summer 1999 to 2000 in the Bay of Fundy, Canada, using suction cup attachment tags (Matthews et al. 2001). Calls classified as 'moans' were described as being broadly in the frequency range 50 to $500 \mathrm{~Hz}$ and lasting 0.4 to $1.5 \mathrm{~s}$. We take these moans to be synonymous with the up-calls produced by North Pacific right whales in the Bering Sea. Although we recognize potential differences between populations of right whales in these 2 ocean basins, the context of the calling, on the feeding grounds and particularly in a social setting, is broadly equivalent. Using acoustic tags attached to 10 different whales (29.5 tag hours in total, cf. Table 4 in Matthews et al. 2001), a weighted average moan production rate of 1.765 calls $\mathrm{h}^{-1}$ was obtained, which is essentially indistinguishable from our estimate.

\section{Implications for right whale management}

This study presents the first abundance estimate for North Pacific right whales based on acoustic data, and is strikingly similar to the numbers recently estimated by other authors (Wade et al. 2011) using mark-recapture techniques for photographic and genetic data. One major question that remains is: To which portion of the North Pacific right whale population do these estimates apply - the eastern or the western stock? North Pacific right whales are among the most endangered whale species on earth, and there remain huge gaps in our knowledge of basic biological information about them, including the location of wintering grounds and population structure. Historic and recent observations support the division of North Pacific right whales into an eastern and a western stock (Brownell et al. 2001, Clapham et al. 2004), and a recent reexamination of data from whaling logbooks corroborates a bimodal distribution of right whales, with very few sightings in the central North Pacific (Josephson et al. 2008). Omura $(1958,1986)$ suggested that the western stock be further divided into 2 subpopulations, one migrating within the Sea of Japan and summering in the Sea of Okhotsk, and another migrating along the Pacific coasts of Japan and the Kamchatka peninsula, with some animals entering the Bering Sea by early summer.

The southeastern Bering Sea middle-shelf region is the only area in the Bering Sea where North Pacific right whales have been detected consistently since 1980, and the assumption in recent literature is that 
these animals belong to the eastern stock of North Pacific right whales, the same stock that was heavily exploited in the 'Northwest' or 'Kodiak' whaling ground in the western Gulf of Alaska. However, sightings of right whales in the Gulf of Alaska have been much rarer in recent decades than in the southeastern Bering Sea, with only 2 individuals uniquely identified by photographs, and neither of these individuals matches any of those photographed in the southeastern Bering Sea (Wade et al. 2011). Thus, the possibility exists that right whales in the Bering Sea belong to a population other than the eastern North Pacific/Gulf of Alaska stock; Brownell et al. (2001) noted that the extent of exchange between the 2 populations (eastern and western) in high latitudes is unknown. Acoustic characteristics of calls themselves are unlikely to shed any light on the population structure of North Pacific right whales, due to the overall similarity of call repertoires across right whale species and oceans and high variability of right whale calls within populations and individuals. However, further acoustic monitoring in potential migration corridors may provide information on the timing and entry/exit locations for right whales that appear in the southeastern Bering Sea every summer, which could aid in determining population affiliation and point to potential habitat areas outside the Bering Sea. Comparison of Bering Sea right whale photographic and genetic data to those obtained from whales in Japanese and Russian waters would be useful for determining stock delineations, but collecting and sharing such data across international boundaries presents some challenges.

\section{CONCLUSIONS}

We have provided an abundance estimate for the North Pacific right whales in the Bering Sea based on passive acoustic monitoring data. Despite the number of shortcomings to this estimate, it seems that a welldesigned passive acoustic survey, with a larger number of randomly allocated sensors, should prove an efficient way to estimate the abundance of this threatened species - in this sense, the current work can be seen as a 'pilot study.'

We envisage that passive acoustics will become, in the near future, a standard way for monitoring cetacean populations under a variety of scenarios. Similar methods are also potentially applicable to a range of terrestrial species. Since the largest proportion of the variance associated with the density estimate is due to cue rate estimation, we strongly recommend dedicated studies which should look at estimating cue rates over time and space.
Acknowledgements. We thank S. Moore and B. Small for providing support. M. McDonald shared data and gave reviews on our analysis. H. Bassett and S. Kerosky assisted in call analysis. J. Barlow provided helpful advice and cruise opportunities. R. LeDuc, L. Ballance, P. Wade, and R. Pitman acted as chief scientists during cetacean surveys. A. Sauter and S. Rankin assisted with acoustics. We thank the officers and crews of the 3 research vessels. P. Stabeno collaborated with incorporation of HARPs into existing biophysical moorings and shared ship time to deploy and recover instruments. Support for ARP and HARP fabrication and deployment was provided by NOAA NMML (JIMO NA17RJ1231), NFWF (2003-0170-017), and ADFG (T-1-6-4). Support for data analysis was provided by NPMRI (T-2100) and NPRB (R0307, F0519). L.T. and T.A.M. were funded under the National Oceanographic Partnership Program (DECAF project) by 2 partners: the Ocean Acoustics Program of the US National Marine Fisheries Service, Office of Protected Resources, and the International Association of Oil and Gas Producers' Joint Industry Programme on Exploration and Production Sound and Marine Life.

\section{LITERATURE CITED}

Amante C, Eakins BW (2009) ETOPO1 1 arc-minute global relief model: procedures, data sources and analysis. NOAA Tech Memo NESDIS NGDC-24, Boulder, CO

Aubauer R, Lammers MO, Au WW (2000) One-hydrophone method of estimating distance and depth of phonating dolphins in shallow water. J Acoust Soc Am 107: 2744-2749

Barlow J, Taylor B (2005) Estimates of sperm whale abundance in the northeastern temperate Pacific from a combined acoustic and visual survey. Mar Mamm Sci 21: 429-445

Borchers DL, Marques TA, Gunnlaugsson T, Jupp PE (2010) Estimating distance sampling detection functions when distances are measured with errors. J Agric Biol Environ Stat 15:346-361

Brownell RL Jr, Clapham PJ, Miyashita T, Kasuya T (2001) Conservation status of North Pacific right whales. J Cetacean Res Manag 2:269-286

Buckland ST (2006) Point transect surveys for songbirds: robust methodologies. Auk 123:345-357

Buckland ST, Anderson DR, Burnham KP, Laake JL, Borchers DL, Thomas L (2001) Introduction to distance sampling estimating abundance of biological populations. Oxford University Press, Oxford

Cato DH (1998) Simple methods of estimating source levels and locations of marine animal sounds. J Acoust Soc Am 104:1667-1678

Clapham PJ, Good C, Quinn SE, Reeves RR, Scarff JE, Brownell RL Jr (2004) Distribution of North Pacific right whales (Eubalaena japonica) as shown by 19th and 20th century whaling catch and sighting records. J Cetacean Res Manag 6:1-6

Gatz DF, Smith L (1995) The standard error of a weighted mean concentration-I. Bootstrapping vs other methods. Atmos Environ 29:1185-1193

Hastie GD, Swift RJ, Gordon JC, Slesser G, Turrell WR (2003) Sperm whale distribution and seasonal density in the Faroe Shetland Channel. J Cetacean Res Manag 5: $247-252$

Johnson MP, Tyack PL (2003) A digital acoustic recording tag for measuring the response of wild marine mammals to sound. IEEE J Oceanic Eng 28:3-12 
Josephson E, Smith TD, Reeves RR (2008) Historical distribution of right whales in the North Pacific. Fish Fish 9: 155-168

Leaper R, Gillespie D, Papastavrou V (2000) Results of passive acoustic surveys for odontocetes in the Southern Ocean. J Cetacean Res Manag 2:187-196

LeDuc R (2004) Report of the results of the 2002 survey for North Pacific right whales. NOAA Fisheries, SWFSC, La Jolla, CA

LeDuc RG, Perryman WL, Gilpatrick JW Jr, Hyde J, Stinchcomb C, Carretta JV, Brownell RL Jr (2001) A note on recent surveys for right whales in the southeastern Bering Sea. J Cetacean Res Manag 2:287-289

Lewis T, Gillespie D, Lacey C, Matthews J and others (2007) Sperm whale abundance estimates from acoustic surveys of the Ionian Sea and Straits of Sicily in 2003. J Mar Biol Assoc UK 87:353-357

Marques TA (2007) Incorporating measurement error and density gradients in distance sampling surveys. $\mathrm{PhD}$ thesis, University of St Andrews

Marques TA, Thomas L, Fancy SG, Buckland ST (2007) Improving estimates of bird density using multiple covariate distance sampling. Auk 124:1229-1243

Marques TA, Thomas L, Ward J, DiMarzio N, Tyack PL (2009) Estimating cetacean population density using fixed passive acoustic sensors: an example with Blainville's beaked whales. J Acoust Soc Am 125:1982-1994

Marques TA, Thomas L, Martin SW, Mellinger DK and others (2010) Spatially explicit capture-recapture methods to estimate minke whale abundance from data collected at bottom-mounted hydrophones. J Ornithol doi:10.1007/ s10336-010-0535-7

Matthews JN, Brown S, Gillespie D, Johnson M and others (2001) Vocalisation rates of the North Atlantic right whale (Eubalaena glacialis). J Cetacean Res Manag 3: 271-282

McDonald MA (2006) Calibration of acoustic recording packages (ARPs) at Pt. Loma Transducer Evaluation Center (TRANSDEC). Scripps Institution of Oceanography Technical Report, La Jolla, CA

> McDonald MA, Fox CG (1999) Passive acoustic methods applied to fin whale population density estimation. J Acoust Soc Am 105:2643-2651

McDonald MA, Moore SE (2002) Calls recorded from North Pacific right whales (Eubalaena japonica) in the eastern Bering Sea. J Cetacean Res Manag 4:261-266

McDonald MA, Hildebrand JA, Webb SC (1995) Blue and fin whales observed on seafloor array in the Northeast Pacific. J Acoust Soc Am 98:712-721

Mellinger DK, Nieukirk SL, Matsumoto H, Heimlich SL and others (2007a) Seasonal occurrence of North Atlantic right whale (Eubalaena glacialis) vocalizations at two sites on the Scotian Shelf. Mar Mamm Sci 23:856-867

Mellinger DK, Stafford KM, Moore SE, Dziak RP, Matsumoto $H(2007 b)$ An overview of fixed passive acoustic observa-

Editorial responsibility: Brendan Godley,

University of Exeter, Cornwall Campus, UK tion methods for cetaceans. Oceanography (Wash DC) 20: $36-45$

Munger LM, Mellinger DK, Wiggins SM, Moore SE, Hildebrand JA (2005) Performance of spectrogram cross-correlation in detecting right whale calls in long-term recordings from the Bering Sea. Can Acoust 33:25-34

Munger LM, Wiggins SM, Moore SE, Hildebrand JA (2008) North Pacific right whale (Eubalaena japonica) seasonal and diel calling patterns from long-term acoustic recordings in the southeastern Bering Sea, 2000-2006. Mar Mamm Sci 24:795-814

Munger LM, Wiggins SM, Hildebrand JA (in press) Right whale 'up-call' source levels and propagation distance on the southeastern Bering Sea shelf. J Acoust Soc Am

Omura H (1958) North Pacific right whale. Sci Rep Whales Res Inst Tokyo 13:1-52

Omura H (1986) History of right whale catches in the waters around Japan. Rep Int Whal Comm Spec Issue 10:35-41

Seber GAF (1982) The estimation of animal abundance, 2nd edn. Griffin, London

Sirovic A, Hildebrand JA, Wiggins SM (2007) Blue and fin whale call source levels and propagation range in the Southern Ocean. J Acoust Soc Am 122:1208-1215

Thomas L, Buckland ST, Rexstad EA, Laake JL and others (2010) Distance software: design and analysis of distance sampling surveys for estimating population size. J Appl Ecol 47:5-14

Van Parijs SM, Clark CW, Sousa-Lima RS, Parks SE, Rankin S, Risch D, Van Opzeeland IC (2009) Management and research applications of real-time and archival passive acoustic sensors over varying temporal and spatial scales. Mar Ecol Prog Ser 395:21-36

Wade PR, Heide-Jørgensen MP, Shelden K, Barlow J and others (2006) Acoustic detection and satellite-tracking leads to discovery of rare concentration of endangered North Pacific right whales. Biol Lett 2:417-419

Wade PR, Kennedy A, LeDuc R, Barlow J and others (2011) The world's smallest whale population? Biol Lett 7:83-85

> Wiggins SM (2003) Autonomous Acoustic Recording Package (ARPs) for long-term monitoring of whale sounds. Mar Technol Soc J 37:13-22

Wiggins SM, Hildebrand JA (2007) High-frequency acoustic recording package (HARP) for broad-band, long-term marine mammal monitoring. In: International Symposium on Underwater Technology 2007 and International Workshop on Scientific Use of Submarine Cables \& Related Technologies 2007. Institute of Electrical and Electronics Engineers, Tokyo, p 551-557

Wiggins SM, McDonald MA, Munger LA, Hildebrand JA, Moore SE (2004) Waveguide propagation allows range estimates for North Pacific right whales in the Bering Sea. Can Acoust 32:146-154

Zimmer WM, Harwood J, Tyack PL, Johnson MP, Madsen PT (2008) Passive acoustic detection of deep diving beaked whales. J Acoust Soc Am 124:2823-2832

Submitted: May 14, 2010; Accepted: November 12, 2010

Proofs received from author(s): February 15, 2011 